\title{
Cuesta, Ubaldo; Peñafiel, Carmen; Terrón, José Luís, Bustamante Edison y Gaspar Sandra (Coords.) (2017): Comunicación y Salud. Madrid: Dextra Editorial. 684 pp. ISBN:978-84 -16898-20-6.
}

Comunicación y Salud es un manual coordinado por Ubaldo Cuesta, Carmen Peñafiel, José Luís Terrón, Edison Bustamante y Sandra Gaspar. A lo largo de sus 684 páginas, más de 40 especialistas entre los que destacan médicos, psicólogos, farmacéuticos y periodistas expertos en salud y comunicación analizan y formulan sus propuestas en un campo que ha experimentando un auge inusitado en los últimos años, motivado por un mayor acceso a la información que demanda el público, los avances tecnológicos y la incorporación de la información en los entornos digitales. La obra está dividida en nueve partes que integran 43 capítulos perfectamente estructurados con el objetivo de contribuir a la convergencia de los ámbitos de la Comunicación y la información de salud en el entorno 2.0.

En la primera parte Bases conceptuales, Sonnenfeld aborda la salud con una perspectiva humanista desde el concepto del sistema motivacional y la posibilidad del ser humano de autorrealizarse o autodestruirse. A su vez, Terrón define el concepto de salud desde el punto de vista institucional, histórico, además del bienestar y estilos de vida. Mientras que Cuesta y Menéndez sientan las bases conceptuales que condicionan el campo de estudio de la salud y los nuevos planteamientos estratégicos.

La II parte desarrolla la Interacción profesional sanitario-paciente. March analiza las claves para una comunicación eficiente entre médico y paciente, así como las técnicas para lograr empatía en una comunicación eficaz. Llamero trata la comunicación entre médico y paciente teniendo en cuenta la abundancia de información accesible en internet y que el paciente en cierto modo cuestiona la credibilidad de los profesionales. Mientras que Sueiro, con un enfoque humanístico plantea aspectos como escuchar, comprender, reflexionar, corregir y en último lugar acompañar y morir, en definitiva humanizar la vida y la muerte. Mendizábal hace hincapié en la alianza entre científicos y pacientes en la comunicación, contemplando los riesgos y beneficios que puede suponer para la salud cuando se habla de terapias experimentales, células madre e incluso el negocio de tratamientos milagro. Erazo-Coronado habla de la importancia de la comunicación interpersonal entre médico paciente en función de las variables de edad, género, etnia, además del lenguaje verbal y no verbal, la empatía adherencia al tratamiento, satisfacción y los resultados en la salud.

La parte III está dedicada a tratar las estrategias desde el ámbito público para la promoción de la salud. En este apartado de comunicación para la salud y eduentretenimiento Jgartua marca los enfoques metodológicos en el estudio del edu-entretenimiento, la investigación formativa, sumativa, así como la evaluación del impacto del edu-entretenimiento. Por su parte, Kaplún desarrolla las estrategias de educomunicación centradas en salud pública, la participación y el diálogo como diferencial estratégico. Ignacio Basagoiti, Manuel Traver y Vicente Traver definen la alfabetización en salud, así como modelos y tipos en términos absolutos y relativos, además de los factores condicionantes, métodos evaluación, consecuencias, estudios poblacionales, barreras en la comunicación y necesidades. Sainz Martín contempla la salud pública teniendo en cuenta los profesionales, legislación, sostenibilidad del gasto sanitario, estrategia Nacional de Salud y presenta nuevos enfoques de la política sanitaria, promoción de la salud, actividades de desarrollo y webs de interés. Alsina y Bravo destacan la importancia de la realidad mediática de las vacunas y su impacto en la sociedad, además del caso de la vacuna frente al virus del papiloma humano. Le sigue Mestre con el capítulo sobre la promoción de la salud desde las administraciones públicas, destacando aspectos como gabinetes de prensa, estrategias de promoción y medios de comunicación en la Comunidad de Madrid.

La parte IV centrada en temas sociales y comunitarias, la autora Tato centra su estudio en el nuevo modelo de paciente, que participa en las decisiones. También hace un recorrido por aspectos sanitarios como la gestión, la calidad del servicio y un decálogo de los pacientes. Saldívar Blanco se centra en la calidad de vida laboral, aproximándose al concepto, la percepción personal, la vida laboral, su motivación, expectativas, socialización y cultura organizacional. La Comunicación e imagen institucional de la Fundación de Ayuda contra la Drogadicción, es otro capítulo en el que Calderón analiza la publicidad social y medios de comunicación, además de las claves para el cambio, los valores y educación, así como la imagen publicitaria de los jóvenes. Asimismo, destaca el éxito de las campañas de la FAD (1988-2016) y la importancia de la adecuación del mensaje al momento histórico y las campañas en las redes. La Comunicación en salud con niños, niñas y adolescentes es tratado por García Pérez. Incluye sus derechos en la praxis médica. Destaca la importancia de la comunicación entre pediatra, paciente, familia, la relación médico paciente y pediatra- niños y la competencia comunicativa y educacional entre el médico el paciente y su familia para lograr cambios en el estilo de vida.

En la parte $V$ comunicación organizacional las autoras Bruno, Demonte y Jait abordan el uso de la comunicación en los procesos de cambio de las 
organizaciones de salud, así como su complejidad y la singularidad del trabajo, la imagen, la organización de redes conversacionales y el posible cambio organizacional. En cuanto a la gestión de la marca en la comunicación institucional hospitalaria Medina Aguerrebere, indica el proceso a través del cual el hospital puede crear una arquitectura de marca, que le permita articular su comunicación institucional para conseguir una reputación corporativa. Rodríguez Andrés presenta las pautas del diseño de los planes de comunicación para organizaciones sanitarias, dando respuesta a la necesidad de la gestión profesional y la comunicación con el fin de relacionarse eficazmente con los medios y trasladar su mensaje a la opinión pública adecuándolos al momento histórico y las campañas en las redes. Por su parte Díaz y Ugarte muestran la comunicación de organizaciones del ámbito de salud desde una perspectiva estratégica y relacional abordando los nuevos actores y retos con el fin de crear unas relaciones fluidas, simétricas y eficaces. Bustamante ofrece un marco de referencia para la comunicación interna en salud destacando la importancia de las relaciones públicas con una propuesta general de comunicación interna para las organizaciones de salud. Arroyave y Erazo desde la perspectiva institucional de la comunicación en salud hacen un recorrido histórico desde el punto de vista institucional, además de las asociaciones, publicaciones, revistas científicas, cursos y otros campos no relacionados con la ciencia.

La parte VI que está dedicada al marketing, publicidad y salud donde Comas se adentra en el desarrollo del marketing sus tácticas y estrategias. Pascual Mollá aborda la comunicación publicitaria institucional en cuanto se refiere a la prevención y tratamiento de drogodependencias, así como límites de la publicidad del alcohol. González-Díaz, Meléndez y Álvarez analiza el auge del mercado de los alimentos funcionales y efectúan un análisis comparativo del contexto regulatorio entre Europa y EE.UU, así como propuestas de mejora de la reglamentación existente. Brugazo y Jiménez nos acercan al discurso publicitario institucional para la prevención y el tratamiento de las drogodependencias y su consumo como hábito social. También analizan la falta de efectividad de las campañas preventivas. En el capítulo de publicidad y salud: posibles correlaciones en (de) construcción Alves presenta un punto conceptual sobre la salud $y$ publicidad como campos independientes.

La parte VII periodismo especializado, Ramírez analiza el encuadre de las noticias de salud, los problemas que se plantean, la perspectiva de género y la salud en los informativos de mayor audiencia en la televisión mexicana. Por su parte, Catalán define el concepto y las áreas de investigación del periodismo especializado en salud, además de las revistas científicas, asociaciones y los colectivos nacionales e internacionales. Solves, Rius y Arcos muestran la representación que tienen las enfermedades raras en la prensa española durante los últimos cinco años. Destacan entre otros aspectos la proximidad, el interés humano, secciones, géneros, encuadres y autoría de la información.

La parte VIII aborda la salud digital. Peñafiel, Echegaray y Ronco nos acercan al tratamiento de la información de salud en el entorno 2.0 como un compromiso ético y profesional. Su investigación se adentra en la calidad, seriedad y rigor de la información de salud online. Además, realizan una revisión teórica de la perspectiva educativa en la red junto con el papel de las instituciones en educación para la salud a través de las TIC, destinadas a los jóvenes y adolescentes. Finalizan con el análisis del tratamiento informativo de los recursos digitales en internet en País Vasco y Navarra dirigido a jóvenes y adolescentes. Por su parte. Pardo estudia la fotografía y enfermedad mental de las imágenes para la comunicación científica y las redes sociales. Se centra en las fotografías médicas, el fotoperiodismo y la imagen de la enfermedad mental en internet. González Eceizabarrena y Menéndez presentan la mHealth como revolución sanitaria del siglo XXI, desde un contexto a nivel mundial con los retos y oportunidades. Destacan el proceso de creación de una app de salud: ideación, desarrollo, publicación y comunicación. Le sigue Jardón con la transformación digital en la comunicación de una organización profesional sanitaria. Plantea un análisis de situación teniendo en cuenta un entorno cambiante en el mundo de la comunicación y de la salud, la segmentación de públicos y la personalización de los contenidos destacando la innovación como seña de identidad. Moreira y Antunes muestran la internacionalización digital de websites de hospitales. Presentan un estudio práctico que incluye los objetivos y fases del proyecto, websites de hospitales, su modelo de evaluación y un informe de internacionalización digital 2015. En social media y salud Ángel González aborda el impacto de la revolución silente en cada uno de los actores de la salud 2.0 como son profesionales, pacientes-población general, hospitales e industria farmacéutica. Le sigue Ruiz Cantero que incluye las conexiones entre los medios de comunicación, la salud, el género, la divulgación de los problemas de salud y las enfermedades inventadas como estrategias de comunicación y comercialización. También trata las evidencias científicas y de género en la publicidad de fármacos en las revistas científicas de medicina e internet. Finaliza con el estudio de caso sobre la terapia hormonal sustitutiva. Basagoiti, MartinezMillana y Vicente Traver abordan el paciente en el mundo digital como consumidor y transmisor de información, además plantean las amenazas del consumo, el intercambio de información sanitaria, el paciente empoderado y la medicina participativa

La parte IX centrada en casos prácticos, Raquel Rodríguez y Luisa Giraldo ofrecen una visión sobre el tratamiento que los medios otorgan al Alzheimer con el fin de determinar si los contenidos aportan elementos de ayuda a los afectados o tienen finalidad educativa. A su vez Barberá muestra los efectos beneficiosos del aceite de oliva en la salud, la 
evolución del sector, la creación de hábitos de consumo, así como su comunicación a los consumidores. Esther Puertas y Mercedes Díaz finalizan con la comunicación en salud en Nicaragua destacando la importancia que tiene para el desarrollo la comunicación y el diseño de estrategias.

Para terminar, Comunicación y Salud llena un vacío informativo en esta área del conocimiento ofreciendo un enfoque multidisciplinar escrito con un estilo claro y ameno, sin perder de vista el rigor científico. Nos encontramos ante una memoria que analiza y da respuesta a los retos que supone la información de salud en el entorno 2.0, así como las nuevas estrategias de promoción de la salud. Por tanto, esta obra conjunta se convierte en un manual imprescindible en el ámbito universitario para profesores como alumnos, así como para profesionales de la comunicación, la medicina y la farmacia.

María Teresa Santos Diez Universidad del País Vasco UPV/EHU. mariateresa.santos@ehu.eus

Recibida: 05-4-2018 Aceptada: 24-4-2018

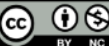

